\title{
REVISTAMATĒRIA
}

ISSN 1517-7076 artigos e13108, 2021

\section{Análise do uso de resíduo da siderurgia para aplicação em cerâmica vermelha através da caracterização química e mineralógica}

\author{
Analysis of the use of steelmaking residue for \\ application in red ceramics through chemical \\ and mineralogical characterization
}

\author{
Laís Cândido da Silva ${ }^{1}$, Alessandra Farias Formiga Queiroga Barreiras ${ }^{2}$, \\ José Sílvio Veras Albuquerque ${ }^{3}$ (In memoriam), Samuel Lucas Santos Medeiros ${ }^{3}$, \\ Ricardo Emílio Ferreira Quevedo Nogueira ${ }^{3}$, Hilder Caldas Ferreira ${ }^{1}$, \\ Marcos Vinícius da Silva Ferreira², Maria Alexsandra de Sousa Rios ${ }^{2}$
}

\footnotetext{
${ }^{1}$ Universidade Federal do Ceará, Departamento de Engenharia Química, Campus do Pici, Bloco 709, CEP: 60455-760, Fortaleza, Ceará, Brasil.

${ }^{2}$ Universidade Federal do Ceará, Departamento de Engenharia Mecânica, Campus do Pici, Bloco 714, CEP: 60455-760, Fortaleza, Ceará, Brasil.

${ }^{3}$ Universidade Federal do Ceará, Departamento de Engenharia Metalúrgica e de Materiais, Campus do Pici, Bloco 729, CEP: 60440-554, Fortaleza, Ceará, Brasil.

e-mail: candido.lais96@gmail.com, hilder.caldas@cspecem.com, aleformiga@yahoo.com.br, viniciusferreira2@outlook.com, alexsandrarios@ufc.br, samuel_engmat@ufc.br; emilio@ufc.br
}

\begin{abstract}
RESUMO
A composição química das cerâmicas tem grande importância no entendimento das propriedades químicas e físicas desse material. Neste trabalho foram realizadas caracterizações química e mineralógica de misturas de argilas, incorporando um resíduo proveniente de uma indústria siderúrgica, para aplicar na produção de cerâmica. Dois tipos de argila foram misturados na proporção de 1:1 e o resíduo foi adicionado nas proporções de $5 \%, 10 \%, 15 \%$ e $20 \%$. Avaliou-se a composição química de cada material puro e a composição mineralógica foi analisada após a etapa de queima, na qual 5 corpos de prova foram submetidos a uma temperatura de $800{ }^{\circ} \mathrm{C}$. A caracterização foi realizada com os ensaios de Fluorescência de Raios X (FRX), Difração de Raios X (DRX), Termogravimetria (TG) e Calorimetria Exploratória Diferencial (DSC). A FRX mostrou os óxidos de silício $\left(\mathrm{SiO}_{2}\right)$ e alumínio $\left(\mathrm{Al}_{2} \mathrm{O}_{3}\right)$ como principais componentes das argilas e os óxidos de ferro $(\mathrm{T}$-Fe, teor de ferro) como principais componentes do resíduo. A DRX mostrou o quartzo como o mineral mais abundante nas argilas, mas que à medida que a concentração de resíduo aumentava na amostra, aumentava também o teor de hematita, principal mineral encontrado no resíduo. A TG e a DSC confirmaram picos esperados nas argilas e identificou uma reação exotérmica nas amostras com resíduo. O aumento do percentual de resíduo provocou alterações na composição química das amostras, no entanto, não foram alterações significativas, o que indica a possibilidade do uso desse resíduo na produção de cerâmica vermelha.
\end{abstract}

Palavras-chave: Cerâmica vermelha, Resíduo siderúrgico, Caracterização.

\section{ABSTRACT}

The chemical composition of ceramics has a deep impact on our understanding of their physical and chemical properties. This work performed a chemical and mineralogical characterization of clay mixtures with incorporation of a residue from the steel industry. The clay mixtures could be used in the brick production. Two types of clays were mixed with the proportion of $1: 1$ and the residue were incorporated with the proportions of $5 \%, 10 \%, 15 \%$, and $20 \%$. Each material had their chemical composition analysed before the burning step. Five specimens were used to analyse their mineralogical composition after the burning step at the temperature of $800{ }^{\circ} \mathrm{C}$. The tests performed to make the characterization were: X-Ray Fluorescence (XRF), X-Ray Diffraction (XRD), Thermogravimetry (TG) and Differential Scanning Calorimetry (DSC). The XFR analy- 
sis showed that the main components of the clays are the silicon oxide $\left(\mathrm{SiO}_{2}\right)$ and the aluminium oxide $\left(\mathrm{Al}_{2} \mathrm{O}_{3}\right)$, and for the residue, the main components are the iron oxides, represented by iron content ( $\left.\mathrm{T}-\mathrm{Fe}\right)$. The XRD analysis showed the quartz as the most abundant mineral in clays, but that hematite, the most abundant mineral in the residue, appeared more as the amount of residue increased in the sample. Thermal Analysis confirmed the expected peaks in clays and identified an exothermic reaction in the sample with residue. The increase in the percentage of residue caused changes in the chemical composition of the samples, however, these variations were not remarkable, which suggests the red clay industry could add the residue in its production.

Keywords: Red ceramic, Steel residue, Characterization.

\section{INTRODUÇÃO}

A importância da preservação do meio ambiente tem estado mais em pauta nos últimos anos. A legislação ambiental se tornou mais rígida e dessa forma, observou-se uma tentativa de redução da quantidade de resíduos sólidos que são despejados na natureza. Esses resíduos são uma preocupação pertinente por parte das indústrias, pois muitas vezes não recebem uma destinação correta.

A Indústria Siderúrgica é um setor, por exemplo, que produz toneladas de resíduos ao ano em apenas uma das etapas do processo produtivo. Uma das alternativas encontradas para essa questão foi o reaproveitamento desses resíduos em outros setores da indústria [1]. Em 2016, 87\% dos coprodutos e resíduos produzidos foram reaproveitados, sendo a indústria cimenteira o setor que mais reaproveita esse tipo de produto [2].

$\mathrm{O}$ alto-forno é um dos principais equipamentos no processo produtivo do aço. Nele ocorre a redução do minério de ferro, formando ferro-gusa. Nesse processo, um gás com alto poder calorífico sai no topo do equipamento e pode ser reaproveitado no processo, no entanto, antes do reaproveitamento é necessário um pré-tratamento para separação do material particulado presente na corrente de gás. Esse tratamento pode ser realizado em equipamentos como Ciclone, Lavador tipo Venturi, Torre de Lavagem, entre outros [3]. Nesse estudo, o resíduo utilizado é oriundo de um sistema de tratamento que utiliza o Ciclone, o que classifica o resíduo como Pó de Ciclone.

Estudos vêm sendo realizados, na tentativa de aliar a necessidade de destinação de um resíduo que não pode ser descartado livremente no ambiente com a diminuição do consumo de matéria-prima da indústria cerâmica. Nesse cenário, inovações como a incorporação dos resíduos da siderurgia na massa cerâmica são amplamente estudadas, seja com resíduos de diferentes etapas da produção do aço, seja com o quanto do material é possível adicionar para que as propriedades do produto acabado estejam ainda dentro dos padrões estabelecidos.

Na produção de cerâmica vermelha, tem-se a argila como principal matéria-prima. O que possibilita seu uso na indústria cerâmica é o fato de desenvolver plasticidade quando umedecida [4, 5]. A composição química das argilas é um importante fator para determinar suas propriedades físicas. Por esse motivo, as argilas passam por caracterizações química, mineralógica e até térmica para estudar os efeitos que essa composição causa ao material final. Uma das técnicas mais utilizadas para realizar a caracterização química é a Fluorescência de Raios X (FRX) e para determinar as fases cristalinas do material cerâmico, a técnica mais comum e eficiente é a Difração de Raios X (DRX). A análise térmica permite avaliar o comportamento dos minerais que compõem a argila em função da temperatura. Ensaios utilizados são a Análise Termogravimétrica (TG) e a Calorimetria Exploratória Diferencial (DSC) [6].

Entendendo a importância dessas análises, esse trabalho avaliou a incorporação de um resíduo do alto-forno de uma indústria siderúrgica, por meio da composição química e mineralógica de uma mistura de dois tipos de argilas (plástica e não plástica). Como principal contribuição para a área, o estudo apresenta os resultados da incorporação de porcentagens do resíduo entre 5 a 20\%, as quais diferem dos quantitativos encontrados na literatura, tais como 3 a 6\% [7, 8], abrindo oportunidade para o aproveitamento de quantitativos maiores do referido resíduo. Foram analisadas e discutidas as alterações químicas e mineralógicas que esse resíduo proporcionou ao produto, de acordo com a quantidade adicionada, visando a determinação de uma porcentagem satisfatória de resíduo que possa ser incorporado na preparação de produtos de cerâmica vermelha. Dessa forma, o aproveitamento de um quantitativo maior do resíduo de alto-forno poderá contribuir significativamente para a redução da disposição desse material na natureza.

\section{MATERIAIS E MÉTODOS}

\subsection{Preparação da massa e corpos de prova}


Nesta pesquisa, foram utilizadas as mesmas argilas do estudo de MAIA [9], que analisou a qualidade de misturas de argila para indústria cerâmica, e identificou que a proporção de $1: 1$, ou seja, $50 \%$ da argila plástica e $50 \%$ da argila não plástica, é a mais favorável para obtenção de boas propriedades físicas. Dessa forma, analisou-se o comportamento da massa cerâmica pura e, também, incorporada com frações de resíduo nas porcentagens de $5 \%, 10 \%, 15 \%$ e $20 \%$.

Seguindo um procedimento similar ao realizado por FERREIRA [10], em seu estudo sobre as propriedades físicas dos corpos cerâmicos incorporados com resíduo da siderurgia, pequenos blocos cerâmicos de peso médio de $80 \mathrm{~g}$ foram produzidos, um de argila pura 1:1 e um para cada proporção de resíduo incorporado, totalizando 5 corpos de prova. Para preparar os blocos, as argilas foram peneiradas em uma peneira de 80 mesh $(177 \mu \mathrm{m})$, para que houvesse um padrão na granulometria dos grãos, foram ainda pesadas e misturadas, adicionando $10 \%$ de água para formar a massa cerâmica [10].

As massas foram conformadas em um molde de dimensões de 115 x 25 x $14 \mathrm{~mm}$ e foram prensadas a 2 toneladas $\left(11,6 \mathrm{kgf} / \mathrm{cm}^{2}\right)$. Em seguida, secaram por $24 \mathrm{~h}$ em uma estufa da marca Medclave a $100{ }^{\circ} \mathrm{C}$ e seguiram para a etapa de queima. Nesta etapa, as amostras foram levadas a um forno elétrico da marca Linn Elektro Therm e queimadas a uma temperatura de $800{ }^{\circ} \mathrm{C}$ por $1 \mathrm{~h}$, com uma taxa de aumento da temperatura de $10^{\circ} \mathrm{C} / \mathrm{min}$. Os corpos de prova podem ser observados na Figura 1.

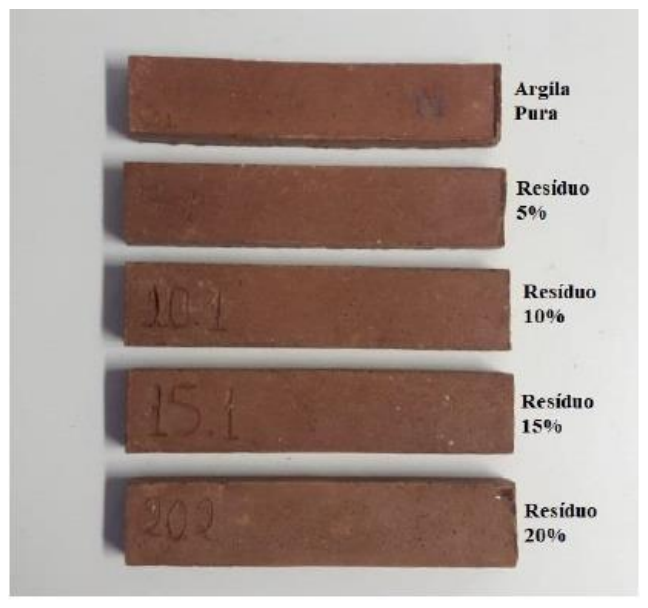

Figura 1: Corpos de prova após a queima.

\subsection{Ensaio de Fluorescência de Raios X (FRX)}

A composição química do resíduo e das duas argilas foi estudada por Fluorescência de Raios X. As amostras puras foram analisadas, ou seja, sem queima, e para melhorar a qualidade dos grãos, foram peneiradas em uma peneira de 200 mesh $(74 \mu \mathrm{m})$. Para determinar o teor dos óxidos de sódio $\left(\mathrm{Na}_{2} \mathrm{O}\right)$ e de potássio $\left(\mathrm{K}_{2} \mathrm{O}\right) \mathrm{o}$ ensaio realizado foi o de Espectrofotometria de Emissão por Plasma (ICP-OES) e para determinar os demais, o ensaio foi o de Espectrofotometria de Fluorescência de Raios X (XRF), utilizando o método da pastilha fundida. As amostras puras foram analisadas em um espectrômetro Rigaku, Simultix 14.

\subsection{Ensaio de Difração de Raios X (DRX)}

Para a determinação da composição mineralógica das argilas e do resíduo, realizou-se um ensaio de difração de raios X na mistura de argilas 1:1, no resíduo puro e nas peças com adição de resíduo que foram conformadas e queimadas. Tais peças foram trituradas e peneiradas em uma peneira de 200 mesh (74 $\mu \mathrm{m})$. A análise ocorreu no Laboratório de Raios X, do Departamento de Física da Universidade Federal do Ceará (UFC), e foi realizada no difratômetro modelo DMAXB -Rigaku, com Raios X de $2 \mathrm{~kW}$, operando a $30 \mathrm{~mA} \mathrm{e} 40 \mathrm{kV}$ e com radiação de tubo de Cobalto (Co), CoK $\alpha 1$ e $\mathrm{CoK} \alpha 2$. O intervalo $2 \theta$ utilizado foi de $5^{\circ}$ a $90^{\circ}$, com passo de $0,013^{\circ}$.

\subsection{Análise Térmica}

A análise térmica foi realizada através da Termogravimetria (TG) e da Calorimetria Exploratória Diferencial (DSC). Assim como para a FRX, as amostras foram analisadas sem queima, e para garantir a qualidade da 
análise, foram peneiradas em uma peneira de 200 mesh $(74 \mu \mathrm{m})$. O ensaio foi realizado no Laboratório de Materiais Avançados da UFC, no equipamento NETZSCH STA, a uma taxa de aquecimento de $10{ }^{\circ} \mathrm{C} / \mathrm{min}$ e fluxo de ar sintético de $50 \mathrm{~mL} / \mathrm{min}$. A faixa de temperatura foi de 50 a $1100{ }^{\circ} \mathrm{C}$.

\section{RESULTADOS E DISCUSSÃO}

\subsection{Fluorescência de Raios X (FRX)}

A Fluorescência de Raios X (FRX) mostra os óxidos mais predominantes nas amostras. O resultado da FRX pode ser observado na Tabela 1.

Percebe-se que para a argila plástica, que o óxido de silício $\left(\mathrm{SiO}_{2}\right)$ possui o maior percentual em relação aos outros elementos, seguido dos óxidos de alumínio $\left(\mathrm{Al}_{2} \mathrm{O}_{3}\right)$ e dos óxidos de ferro, resumidos como teor de ferro (T-Fe). Esses percentuais estão de acordo com o que é encontrado na literatura [11-13]. Percebe-se também a presença de óxidos fundentes $\left(\mathrm{K}_{2} \mathrm{O}, \mathrm{Na}_{2} \mathrm{O}, \mathrm{CaO}\right.$ e $\left.\mathrm{MgO}\right)$, porém em baixas concentrações, cuja soma resulta em $7,074 \%$.

Tabela 1: FRX dos dois tipos de argila e do resíduo Pó de Ciclone.

\begin{tabular}{|c|c|c|c|c|c|c|c|c|c|c|c|}
\hline \multirow{2}{*}{ MATERIAL } & \multicolumn{1}{|c|}{ ICP (\%) } & \multicolumn{10}{c|}{ FRX (\%) } \\
\hline & $\mathrm{K}_{2} \mathrm{O}$ & $\mathrm{Na}_{2} \mathrm{O}$ & $\mathrm{Al}_{2} \mathrm{O}_{3}$ & $\mathrm{CaO}$ & $\mathrm{MgO}$ & $\mathrm{MnO}$ & $\mathrm{P}_{2} \mathrm{O}_{5}$ & $\mathrm{SiO}_{2}$ & $\mathrm{~T}-\mathrm{Fe}$ & $\mathrm{TiO}_{2}$ \\
\hline Argila plástica & 1,529 & 0,987 & 19,307 & 1,943 & 2,615 & 0,089 & 0,078 & 53,063 & 5,110 & 1,413 \\
\hline Argila não plástica & 2,25 & 1,568 & 17,003 & 1,337 & 1,293 & 0,080 & 0,097 & 61,924 & 3,404 & 1,094 \\
\hline Pó de Ciclone & 0,456 & 0,532 & 2,208 & 4,705 & 0,584 & 0,222 & 0,098 & 6,944 & 37,787 & 0,130 \\
\hline
\end{tabular}

Da mesma forma que a argila plástica, percebe-se a predominância dos óxidos de silício $\left(\mathrm{SiO}_{2}\right)$, alumínio $\left(\mathrm{Al}_{2} \mathrm{O}_{3}\right)$ e ferro (T-Fe), respectivamente, na argila não plástica. Nota-se, porém, que o teor do óxido de silício se sobressai em relação ao teor apresentado na argila plástica. O mesmo não ocorre com os óxidos de alumínio e de ferro, que apresentam uma queda em relação à argila mais plástica, assim como o teor de óxidos fundentes, que somam $6,448 \%$.

Os óxidos de silício e de alumínio, tanto na argila plástica como na não plástica, podem indicar a presença dos argilominerais caulinita, esmectita ou haloisita, mas também podem ser atribuídos à presença de quartzo e feldspato. A caulinita é um dos principais argilominerais, sendo o componente responsável por conferir plasticidade à argila quando misturada com água. $\mathrm{O}$ quartzo, por sua vez, confere menos plasticidade $[12,13]$. As duas argilas utilizadas neste trabalho apresentam altos teores de óxido de silício $\left(\mathrm{SiO}_{2}\right)$, principalmente a argila não plástica, que possui o maior teor desse óxido entre as duas, porém, o fato de possuir menor quantidade do óxido de alumínio indica que, na verdade, a sílica $\left(\mathrm{SiO}_{2}\right)$ pode ser proveniente do quartzo e não da caulinita, já que o óxido de alumínio está mais relacionado a presença do argilomineral [13, 14].

Os óxidos de ferro (T-Fe) podem indicar a presença dos argilominerais goethita e hematita, mas pode também estar substituindo os cátions de $\mathrm{Al}^{3+}$ nas camadas octaédricas da esmectita $[12,14,15]$. Os óxidos de ferro, de titânio $\left(\mathrm{TiO}_{2}\right)$, de cálcio $(\mathrm{CaO})$ e de magnésio $(\mathrm{MgO})$ são comumente relacionados à cor que a cerâmica vermelha adquire após a queima [13]. Percebe-se que a argila plástica apresenta maiores percentuais para esses óxidos que a argila não plástica.

Os óxidos de sódio $\left(\mathrm{Na}_{2} \mathrm{O}\right)$, potássio $\left(\mathrm{K}_{2} \mathrm{O}\right)$, cálcio $(\mathrm{CaO})$ e magnésio $(\mathrm{MgO})$ são considerados óxidos fundentes e indicam a presença de dolomita, calcita ou feldspato [12, 16]. Altas concentrações desses óxidos podem garantir uma maior resistência aos materiais cerâmicos [13]. Nota-se que a argila plástica possui uma concentração maior desses óxidos somados, mesmo com a argila não plástica possuindo uma maior quantidade do óxido de potássio. Em relação aos óxidos de manganês $(\mathrm{MnO})$ e fósforo $\left(\mathrm{P}_{2} \mathrm{O}_{5}\right)$, observa-se que são os que possuem menores teores nos dois tipos de argilas, o que é compatível com outros trabalhos [12, 17].

Analisando os resultados obtidos para o resíduo Pó de Ciclone, percebe-se que o teor de ferro é o maior dentre os óxidos analisados. Isso se deve ao fato de o ferro ser a matéria-prima básica para a produção do aço, como já mencionado anteriormente. Como se trata de um material que varia de acordo com a indústria e com os tipos de matérias-primas sendo utilizadas para produzir o ferro-gusa no alto-forno, a caracterização desse resíduo acaba sendo única e dificilmente compatível em todos os aspectos com outros resíduos de side- 
rurgia trabalhados em estudos diferentes, no entanto, percebe-se a tendência da alta porcentagem de óxidos de ferro em trabalhos realizados para outros tipos de resíduos do alto-forno $[11,18]$. Os demais óxidos que se destacam são: silício $\left(\mathrm{SiO}_{2}\right)$, com 6,944\%, cálcio $(\mathrm{CaO})$, com 4,705\%, e alumínio $\left(\mathrm{Al}_{2} \mathrm{O}_{3}\right)$, com 2,208\% .

Com a incorporação do resíduo na mistura de argilas 1:1 é esperado um aumento nos teores desses óxidos mais predominantes na massa cerâmica, como os óxidos de ferro $(\mathrm{T}-\mathrm{Fe})$ e de cálcio $(\mathrm{CaO})$, por exemplo.

\subsection{Difração de Raios X (DRX)}

A análise de Difração de Raios $\mathrm{X}$ foi realizada em todas as amostras, tanto nas argilas puras, com e sem queima, no resíduo, sem queima, e nas amostras com 5\%, 10\% 15\% e 20\% de resíduo, com queima. Para facilitar a interpretação, apenas os minerais mais abundantes, com maior número de fases, foram apresentados.

Na Figura 2 - (a), relacionada à argila 1:1 pura sem queima, observa-se uma grande predominância do quartzo e de um mineral do grupo do feldspato, a albita. O quartzo é composto por sílica, o que torna sua presença coerente com o resultado da análise da composição química.

A presença de feldspato também é coerente, pois esse mineral é composto por grupos de silicatos de sódio, potássio e cálcio, elementos que aparecem na Fluorescência de Raios X [5]. A caulinita aparece bem identificada nos picos entre $10^{\circ} \mathrm{e} 15^{\circ}$ e $20^{\circ}$ e $25^{\circ}$. Já o pico entre $5^{\circ}$ e $10^{\circ}$ não pode ser identificado nessa amostra, porém, pode indicar a presença de minerais da classe dos filossilicatos, como mica e esmectita, pois qualquer um desses minerais pode apresentar pico nessa região [5, 12, 13, 15, 19].

A Figura 2 - (b) mostra o resultado da difração para a argila 1:1 pura, que foi conformada e queimada a $800{ }^{\circ} \mathrm{C}$. Observa-se que ainda ocorre a predominância do quartzo e da albita, mineral da família do feldspato. Nota-se, também, que o pico da caulinita entre $10^{\circ}$ e $15^{\circ}$ some, isso ocorre pois a $500{ }^{\circ} \mathrm{C}$ a caulinita começa a passar por reações resultando no desaparecimento das reflexões basais desse argilomineral [5]. É possível observar ainda que alguns picos de quartzo e albita entre $25^{\circ}$ e $30^{\circ}$ se tornam menos intensos, indicando que o aquecimento pode proporcionar reações nesses dois minerais. Por volta de $40^{\circ}$ aparece um pico identificado com o mineral flogopita, um filossilicato do grupo da mica e que apresenta potássio, magnésio e alumínio na fórmula. É importante ressaltar que o programa não oferece um resultado exato e, portanto, que o mineral presente na amostra pode não ser a flogopita, mas sim algum outro componente que possua fórmula molecular parecida ou da mesma família de minerais. Esse resultado é possível, principalmente pela dificuldade na diferenciação de alguns minerais dentro de uma mesma família. SILVA [20] relatou um problema para selecionar o mais preciso dentre dois minerais da família dos feldspatos plagioclásicos, albita e anortita, em alguns picos de uma análise de DRX, mostrando assim, que o programa aponta as soluções mais admissíveis, mas que em alguns picos é possível que a análise não seja tão precisa [20].

O resíduo, cujo difratograma é mostrado na Figura 2 - (c), possui altos teores de ferro tornando coerente a predominância da hematita, mineral composto pelo óxido $\mathrm{Fe}_{2} \mathrm{O}_{3}$. A magnetita, composta por $\mathrm{Fe}_{3} \mathrm{O}_{4}$, também é identificada em muitas fases do difratograma. Outros minerais presentes são o quartzo e um mineral identificado como andradita, um silicato cuja fórmula molecular apresenta cálcio e ferro. Esses compostos são coerentes com os resultados da Fluorescência de Raios X, que indicam uma grande quantidade de ferro, mas também apresenta sílica e cálcio. O resultado também é coerente com outros trabalhos sobre resíduo do alto-forno de uma indústria siderúrgica [11]. 


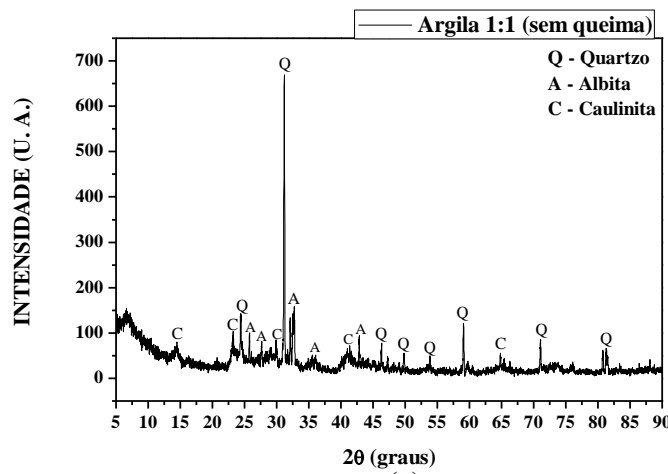

(a)

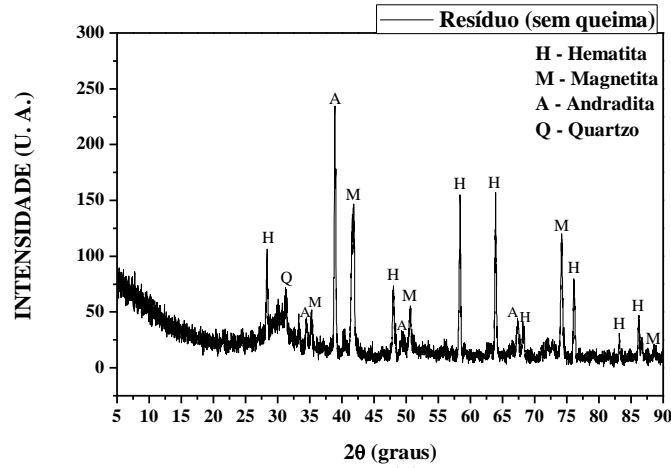

(c)

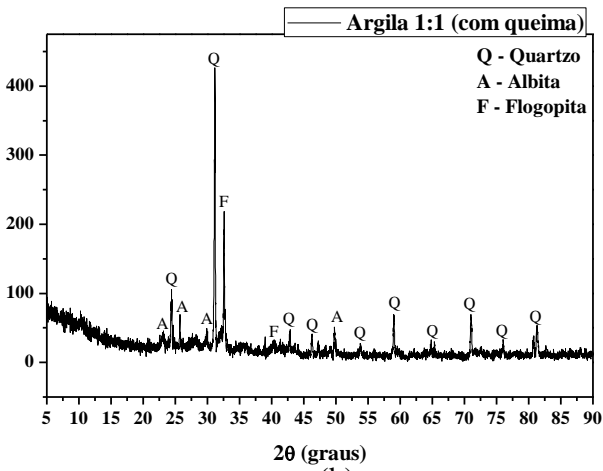

(b)

Figura 2: Difratograma da argila 1:1 - (a) sem queima; (b) com queima; e do resíduo (c).

Os resultados apresentados pelas amostras com 5\%,10\%, 15\% e 20\% de resíduo podem ser observados na Figura 3. Nas amostras de $5 \%$ (a), $10 \%$ (b) e $15 \%$ (c) nota-se um pico por volta de $10^{\circ}$, sendo mais intenso nas amostras de $5 \%$ e $15 \%$. Esse pico foi relacionado ao filossilicato flogopita. É interessante notar que esse pico não é intenso na amostra com $10 \%$, quase não sendo identificado, e não aparece no difratograma da amostra de $20 \%$ (d). Como esse pico não possui grande intensidade e está associado a um mineral da família das micas, que são bastante comuns nas argilas, é possível considerar que essa diferença entre as amostras não proporcione grandes mudanças na avaliação mineralógica dos produtos.

Quanto à composição mineralógica, percebe-se a recorrência dos mesmos minerais que ocorrem na argila pura, o quartzo e a albita. Observa-se, porém, que apenas nas amostras com $15 \%$ e $20 \%$ de resíduo a quantidade de óxido de ferro $\left(\mathrm{F}_{2} \mathrm{O}_{3}\right)$ passa a ser mais relevante. A hematita torna-se ainda mais abundante com o aumento do resíduo, como esperado. 


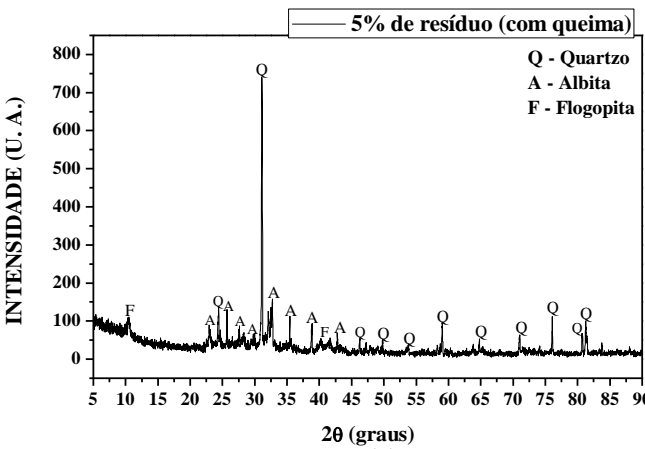

(a)

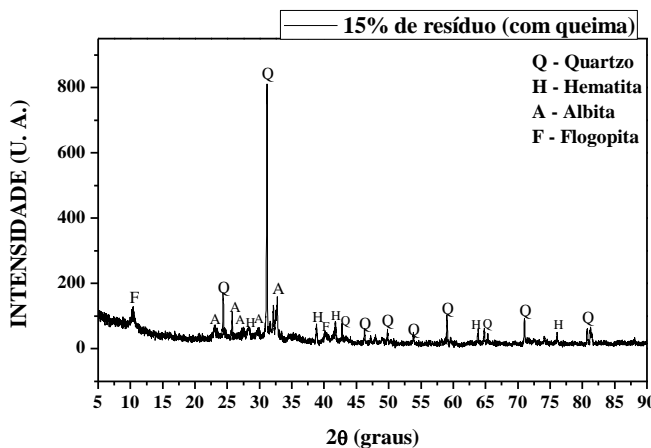

(c)

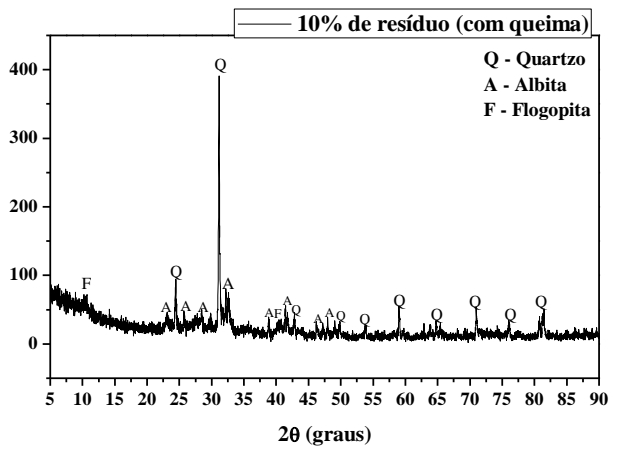

(b)

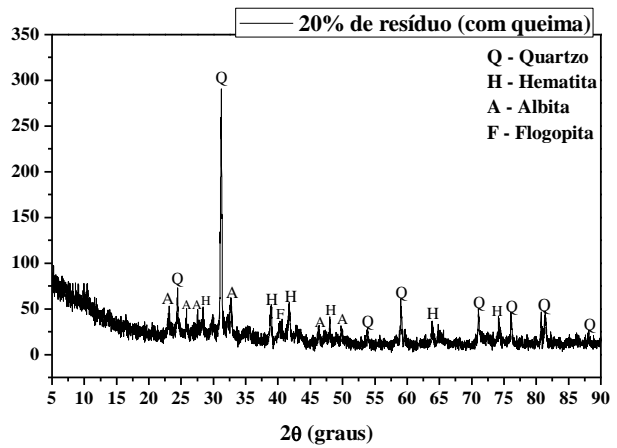

(d)

Figura 3: Difratograma das amostras com - (a) 5\%; (b) 10\%; (c) 15\%; e (d) 20\% de resíduo.

\subsection{Análise Térmica}

As análises de TG e DSC são úteis para visualizar picos endotérmicos e exotérmicos relacionados à variação de massa, no caso da TG, e variação de energia, no caso da DSC. É possível notar em todos os gráficos, um pico endotérmico acentuado variando na faixa de $80{ }^{\circ} \mathrm{C}$ a $90{ }^{\circ} \mathrm{C}$. Esse pico está relacionado à evaporação da água. Na faixa de $470{ }^{\circ} \mathrm{C}$ a $482{ }^{\circ} \mathrm{C}$ observa-se um novo pico endotérmico, possivelmente relacionado à desidroxilação dos argilominerais, que costuma ocorrer entre $300^{\circ} \mathrm{C}$ e $550{ }^{\circ} \mathrm{C}[5,14,16,21]$.

Analisando a curva de DSC na Figura 4, que corresponde à argila pura 1:1, nota-se que há um pico endotérmico a $574,4{ }^{\circ} \mathrm{C}$. A mudança da fase cristalina do quartzo de $\alpha$ para $\beta$ costuma acontecer por volta dessa temperatura, alguns trabalhos indicam essa mudança nas temperaturas de $570{ }^{\circ} \mathrm{C}, 573{ }^{\circ} \mathrm{C}$ ou até mesmo $575{ }^{\circ} \mathrm{C}[14,16,17,21,22]$, sendo possível, então, que o mesmo ocorra para a mistura de argilas estudada nesse trabalho.

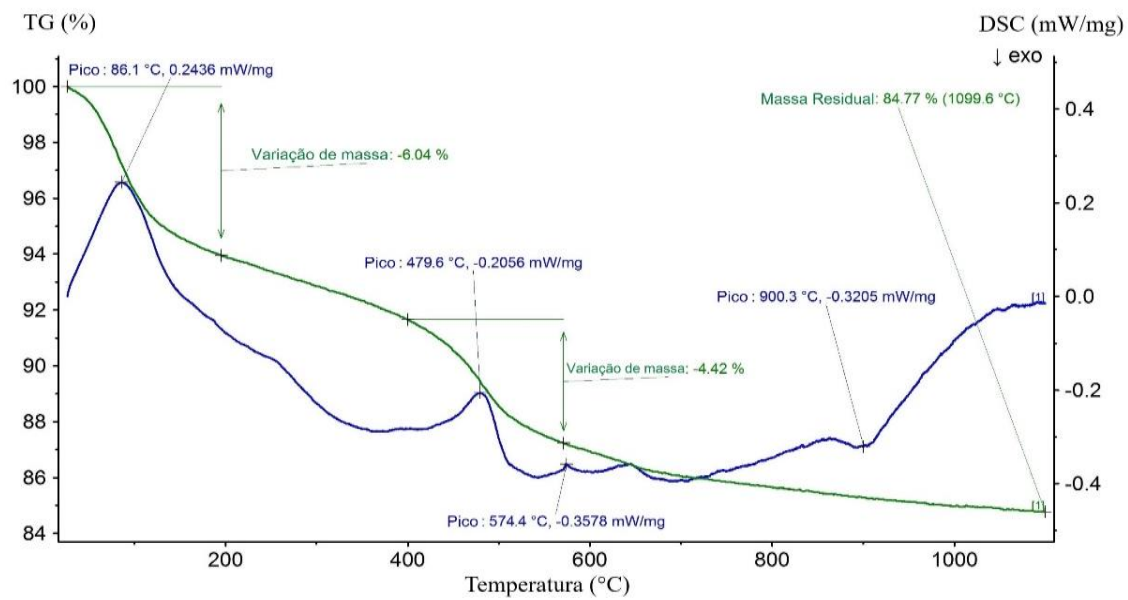

Figura 4: TG e DSC para a argila 1:1 pura. 
Na Figura 5, é estabelecido um comparativo entre a curva TG da mistura sem resíduo com as curvas TG das amostras com resíduo. Na faixa de temperaturas de $600{ }^{\circ} \mathrm{C}$ a $800{ }^{\circ} \mathrm{C}$ ocorre um pico de reação exotérmica apenas nas amostras com resíduo. Isso indica que acontece uma reação característica para esse material. Em outro estudo sobre resíduo do alto-forno, realizado por VIEIRA et al. [11], associa-se essa reação à combustão dos finos de coque. A Figura 6 , mostra a DSC para todas as amostras e evidencia que a reação exotérmica ocorre nas temperaturas variando de $686,8{ }^{\circ} \mathrm{C}$ a $692,1{ }^{\circ} \mathrm{C}$, que se aproxima ainda mais do resultado obtido por VIEIRA et al. [11], um pico a $677,6^{\circ} \mathrm{C}$. SANTOS [5] sugere que o carbono tipo grafita possui picos exotérmicos com máximo até $700{ }^{\circ} \mathrm{C}$ e considerando que o coque, matéria-prima alimentada no alto-forno, é produzido a partir de carbono, pode-se dizer que a combustão de finos do coque é uma explicação plausível para o pico exotérmico apresentado pelas amostras com resíduo [5].

Analisando ainda a Figura 6, observa-se outro pico exotérmico, mas de menor intensidade, a $904{ }^{\circ} \mathrm{C}$, essa é uma reação comum a todas as amostras. Entende-se que é uma reação relacionada à argila. Essa faixa de temperatura pode caracterizar a nucleação da mulita, mais especificamente a etapa da formação da fase espinélio a partir da metacaulinita $[5,16,21]$.

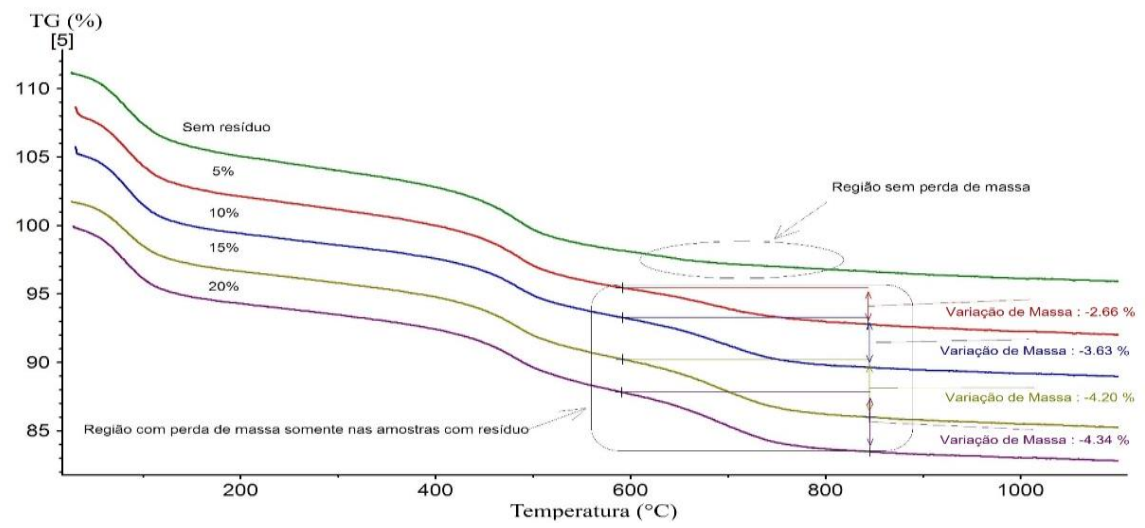

Figura 5: TG - Comparativo entre as curvas.

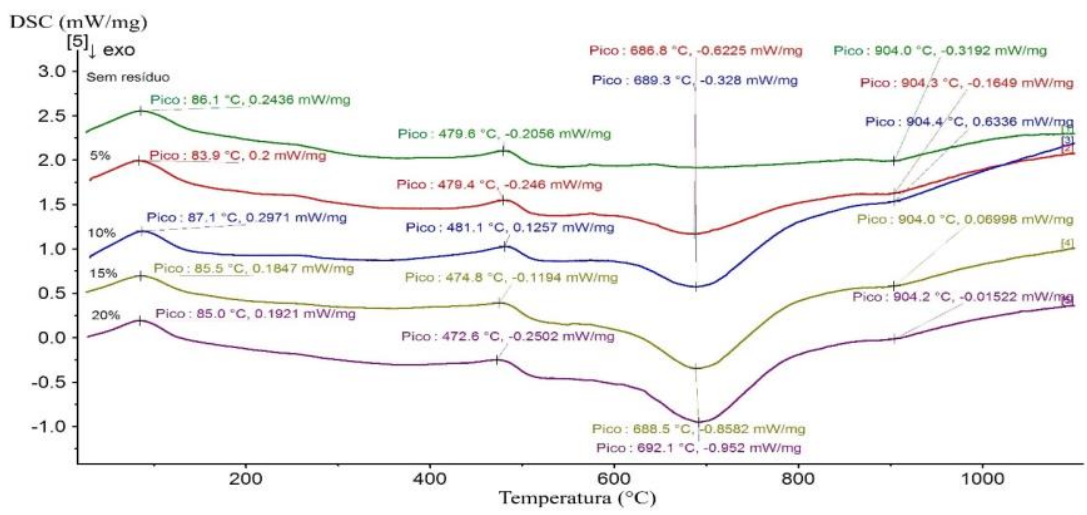

Figura 6: DSC - Comparativo entre as curvas.

\section{CONCLUSÕES}

A análise de Difração de Raios X se mostrou coerente com a análise química resultante da Fluorescência de Raios X. O óxido de silício $\left(\mathrm{SiO}_{2}\right)$ foi o componente de maior abundância na composição dos dois tipos de argilas, seguido do óxido de alumínio $\left(\mathrm{Al}_{2} \mathrm{O}_{3}\right)$. Esses óxidos podem apontar a presença da caulinita e do quartzo, assim como foi identificado nas fases da difração, sendo o quartzo o mineral que apareceu com mais abundância e intensidade. A presença do feldspato confirmou a ocorrência dos óxidos fundentes $\left(\mathrm{Na}_{2} \mathrm{O}\right.$, $\mathrm{K}_{2} \mathrm{O}, \mathrm{CaO}$ e $\mathrm{MgO}$ ) que somados possuem uma porcentagem considerável nas argilas.

A Difração de Raios X apontou também que a quantidade de ferro aumentou conforme a quantidade adicionada de resíduo, o que também é coerente, dado que os óxidos de ferro são os principais componentes do resíduo. Notou-se, porém, que a hematita, mineral que aponta a presença do ferro, só se tornou significati- 
va a partir da adição de $15 \%$ de resíduo. A principal alteração que a hematita pode trazer ao material é na coloração, pois o óxido de ferro torna a cerâmica mais avermelhada. Os resultados mostraram, no entanto, que não houve variação visual significante entre os blocos produzidos, sendo um resultado interessante, pois a aparência do produto cerâmico é um dos fatores que os consumidores avaliam na compra.

A Termogravimetria (TG) e a Calorimetria Exploratória Diferencial (DSC) mostraram que o resíduo não alterou as reações que ocorrem na argila com o aumento de temperatura. A massa residual, no entanto, é menor nas amostras com resíduo, mas constatou-se que não houve uma relação direta entre a quantidade de resíduo adicionado e a perda de massa. As curvas apontaram também uma reação exotérmica que ocorreu apenas nas amostras com resíduo, podendo ser atribuída à combustão dos finos de coque. Essa reação exotérmica pode encobrir reações endotérmicas das argilas e, consequentemente diminuir a energia necessária para que ocorram essas reações.

Os resultados obtidos nas análises levaram à conclusão de que a massa cerâmica preparada com a adição de resíduo pode oferecer aplicações como cerâmica vermelha, pois a adição de 5\% e $10 \%$ não ofereceu mudanças significativas na composição da massa cerâmica e a adição de $15 \%$ e $20 \%$ de resíduo apresentaram apenas um aumento de hematita na mineralogia das massas cerâmicas. Os resultados da análise química, mineralógica e térmica não detectaram aumento em componentes que possam alterar de forma negativa as propriedades mecânicas do produto, portanto, é possível dizer que as porcentagens de resíduo testadas podem ser de fato aplicadas. Ressalta-se, porém, que os ensaios físico-mecânicos se fazem necessários para atestar que o produto esteja dentro de todas as especificações.

\section{BIBLIOGRAFIA}

[1] ALMEIDA, M.L.B., MELO, G.C.B., “Alternativas de Usos e Aplicações dos Resíduos Sólidos das Indústrias Independentes de Produção de Ferrogusa do Estado de Minas Gerais”, In: Congresso Brasileiro de Engenharia Sanitária e Ambiental, 21 ${ }^{\circ}$ Feira Internacional de Tecnologias de Saneamento Ambiental, João Pessoa, Paraíba, Brasil, 16-21 de setembro de 2001.

[2] CNI - Confederação Nacional da Indústria, IABr - Instituto Aço Brasil, A Indústria do Aço no Brasil, Brasília, DF, 2017.

[3] SILVA, C.S.W., Avaliação Ambiental Decorrente do Uso Agrícola de Resíduos do Sistema de Limpeza de Gases de uma Indústria Siderúrgica a Carvão Vegetal, Dissertação de M.Sc., Programa de Pós-Graduação em Fitotecnia, Universidade Federal de Viçosa, Viçosa, MG, Brasil, 2007.

[4] MORENO, M.M.T., ARGILAS: Composição Mineralógica, Distribuição Granulométrica e Consistência de Pastas, Tese de Livre-Docente, Instituto de Geociências e Ciências Exatas, Universidade Estadual de São Paulo, São Paulo, SP, Brasil, 2012.

[5] SANTOS, P.S., Ciência e Tecnologia de Argilas - Volume 1, 2 ed., Editora Edgard Blücher Ltda., São Paulo, SP, 1989.

[6] DENARI, G.B., CAVALHEIRO, E.T.G., Princípios e aplicações de análises térmicas, Instituto de Química de São Carlos (IQSC), Universidade de São Paulo, São Carlos, São Paulo, 2012.

[7] OLIVEIRA, J.E., HOLANDA, J.N.F., "Reaproveitamento de resíduo sólido proveniente do setor siderúrgico em cerâmica vermelha", Cerâmica, v.50, n.314. 2004.

[8] FERREIRA, T.S., ATAIDES, J.A., SILVA, M.A.D., et al. "Reaproveitamento do pó de balão da indústria siderúrgica como matéria prima na cerâmica vermelha", 10 Fórum Internacional de Resíduos Sólidos, 12 a 14 Junho, João Pessoa, PB, Brasil, 2019.

[9] MAIA, F.A.M., Análise das Propriedades Físicas das Misturas Cerâmicas utilizadas na Indústria de Cerâmica Vermelha, Trabalho de Conclusão de Curso, Departamento de Engenharia Mecânica da Universidade Federal do Ceará, Fortaleza, CE, Brasil, 2018.

[10] FERREIRA, M.V.S., Análise das Propriedades Físicas de Corpos Cerâmicos incorporados com Resíduo Siderúrgico, Trabalho de Conclusão de Curso, Departamento de Engenharia Mecânica da Universidade Federal do Ceará, Fortaleza, CE, Brasil, 2019.

[11] VIEIRA, C.M.F., DIAS, C.A.C.M., MOTHÉ, A.V., et al. "Incorporação de Lama de Alto-Forno em Cerâmica Vermelha", Cerâmica [online], v.53, n.328, pp. 381-387. 2007.

[12] ACEVEDO, N.I.A., ROCHA, M.C.G., BERTOLINO, L.C., "Mineralogical characterization of natural clays from Brazilian Southeast region for industrial applications", Cerâmica, v. 63, n. 366, pp. 253-262, Abr/Jun. 2017. 
[13] PRADO, C.M.O., Caracterização Química e Mineralógica das Argilas Utilizadas na Produção de Cerâmica Vermelha no Estado de Sergipe, Dissertação de M.Sc., Núcleo de Pós-Graduação em Química, Universidade Federal de Sergipe, São Cristóvão, SE, Brasil, 2011.

[14] RAMOS, S.O., DANTAS, G.C.B., LIRA, H.L., et al. "Caracterização de argilas de novos jazimentos situados em Parelhas/RN, Brasil, visando aplicação na indústria cerâmica”, Matéria, v. 24, n. 02, Jun. 2019.

[15] PEREIRA, I.D.S., SILVA, I.A., CARTAXO, J.M., et al. "Estudos de caracterização dos novos depósitos de argilas esmectíticas do município de Sossego, PB", Cerâmica, v. 60, n. 354, pp. 223-230, Abr/Jun. 2014.

[16] BRITO, I.P., ALMEIDA, E.P., NEVES, G.A., et al. "Avaliação de novos depósitos de argilas do Estado da Paraíba visando sua aplicação como matérias-primas cerâmicas", Cerâmica, v. 61, n. 360, pp. 391-398, Out/Dez. 2015.

[17] GALÁN-ARBOLEDAS, R.J., DE DIEGO, J.A., DONDI, M., et al. "Energy, environmental and technical assessment for the incorporation of EAF satinless steel slag in ceramic building materials", Journal of Cleaner Production, v. 142, Part 4, pp. 1778-1788, Jan. 2017.

[18] OLIVEIRA, F.R., SILVEIRA, C.S., ASSIS, P.S., "Análise da Lama de Alto-forno como Insumo em Siderúrgicas e Cerâmicas.”, Revista Eletrônica de Materiais e Processos, v. 12, n. 01, pp. 21-25. 2017.

[19] MACEDO, R.S., MENEZES, R.R., NEVES, G.A., et al. "Estudo de argilas usadas em cerâmica vermelha", Cerâmica [online], v. 54, n.332, pp. 411-417. 2008.

[20] SILVA, A.L, Caracterização mineralógica por difração de Raios X e determinação de terras raras por $I C P-M S$ de rochas da região sul da Bahia, Dissertação de M.Sc., Programa de Pós-Graduação em Ciências e Técnicas Nucleares, Universidade Federal de Minas Gerais, Belo Horizonte, MG, Brasil, 2013.

[21] MAIA, L.J.Q., MARTINS, T.A., GESICKI, A.L.D., et al. "Caracterização Térmica de Argilas da Cidade de Costa Rica no Estado de Mato Grosso do Sul", In: Anais do $44^{\circ}$ Congresso Brasileiro de Cerâmica, São Pedro, São Paulo, Brasil, 31 de maio a 4 de junho de 2000.

[22] SAMAL, S., RAY, A.K., BANDOPADHYAY, A., "Characterization and Microstructure Observation of Sintered Red Mud-fly Ash Mixtures at Various Elevated Temperature", Journal of Cleaner Production, v. 101, pp. 368-376, Aug. 2015.

\section{ORCID}

Laís Cândido da Silva

Alessandra Farias Formiga Queiroga Barreiras

José Silvio Veras Albuquerque

Samuel Lucas Santos Medeiros

Ricardo Emílio Ferreira Quevedo Nogueira

Hilder Caldas Ferreira

Marcos Vinícius da Silva Ferreira

Maria Alexsandra de Sousa Rios http://orcid.org/0000-0003-3777-5814

http://orcid.org/0000-0002-0679-7773

http://orcid.org/0000-0003-1869-4824

http://orcid.org/0000-0003-1997-3331

http://orcid.org/0000-0002-2000-4426

http://orcid.org/0000-0002-7607-073X

http://orcid.org/0000-0003-0673-0592

https://orcid.org/0000-0002-3145-0456 